\title{
The Pattern of Adherence to Personal Protective Equipment (PPE) in Jordanian Small and Medium Sized Construction Sites
}

\author{
Dr. Khair Al-Deen Bsisu ${ }^{1}$ \\ ${ }^{1}$ The University of Jordan, School of Engineering, \\ Department of Civil Engineering, Amman, Jordan.
}

ORCID: 0000-0002-3064-9367 (Khair Al-Deen Bsisu)

\begin{abstract}
:
Personal Protective Equipment (PPE) are considered a major element in ensuring the safety of engineers and workers at construction sites. Reports representing on-site injuries among construction workers show limited adherence to safety guidelines and PPE utilization. The aim of this study is to investigate the pattern of PPE use in Jordanian construction sites and the factors related to the adherence and non-adherence to occupational safety rules. I conducted a cross-sectional study on Jordanian civil engineers using an online structured selfadministered questionnaire. 119 engineers with a mean age of $36.2 \pm 12.5$ years were included, of which $98(82.4 \%)$ were males and $21(17.6 \%)$ were females. The most available safety tool were helmets $(73.9 \%)$, followed by safety boots $(66.4 \%)$ and scaffolds $(63 \%)$, while $14.3 \%$ had no safety tools at the construction site. A significant correlation was found between adherence to occupational safety and attending occupational safety workshops $(\mathrm{p}=0.002)$ and first aid workshops $(\mathrm{p}=0.007)$. The main factor to be linked to non-adherence of workers to safety rules was the lack of formal punishment for nonadherence $(67.2 \%)$. Engineers confidence in the effectiveness of safety policies was significantly associated with the awareness of workers $(\mathrm{r}=0.277, \mathrm{p}=0.002)$, awareness of engineers $(r=0.363, p<0.001)$, and the adherence of coworkers ( $\mathrm{r}=0.34, \mathrm{p}<0.001)$. In conclusion, construction industry is one of the main pillars of the national economy of Jordan, and adherent workers play a significant role in the improvement of occupational safety, and therefore Jordanian construction industry.
\end{abstract}

Keywords: Personal Protective Equipment; construction; workers; ergonomics; civil engineering.

\section{INTRODUCTION}

According to the International Labor Organization, more than 270 million of work place injuries occur each year [1], and construction workers have one in three hundred chances of death while at workplace, and their risk of becoming handicapped is higher than that in other industries [2]. These construction site injuries might result in suffering among those workers and their colleagues, leading to reduction in their productivity and quality of life [1].

Personal Protective Equipment (PPE) play a major role in ensuring the safety and health of engineers and workers during the ongoing construction work. Nonetheless, reports demonstrating the numbers and types of on-site injuries, in addition to observations of the adherence of project personnel show limited adherence to safety guidelines and PPE utilization [3]. There are several factors related to the non-adherence to safety guidelines. For instance, Tanko and Anigbogu (2012) demonstrated that workers in Nigeria understood the need to use the PPE, but the issues of comfort and equipment interference with their productivity limited their use [4]. Furthermore, Hashim and May (2018) stated that some PPE equipment like helmets and safety boots are more frequently used than other PPE such as nose masks and eye goggles because they are uncomfortable, interfere with their work and reduce productivity [5]. Moreover, Muema (2017) found that construction workers in Kenya do not receive proper safety training or PPE, which are needed to provide protection against occupational hazards [6].

There is a good understanding of the pattern and extent of occupational accidents and incidents in the construction industry. However, only limited information regarding factors contributing to the non-adherence to safety guidelines is available [7]. The aim of this study is to explore the pattern of PPE use in small and medium sized construction sites in Jordan, in addition to investigating factors related to the adherence and non-adherence to occupational safety rules.

\section{METHODOLOGY}

\subsection{Study Objectives}

The objectives of this study is to construct a questionnaire to find out the availability of PPE on construction sites, the level of awareness of the construction projects engineering staff and workers in Jordan and the degree of adherence by them to the regulations and relate that with several factors of influence. 


\subsection{Study design}

This cross-sectional study was conducted between June 2019 and July 2019 using an online structured self-administered questionnaire. The questionnaire was designed using Google Forms, and sent to civil engineers working at different Jordanian housing and engineering institutions in the Hashemite Kingdom of Jordan.

\subsection{Collected data}

The first section of the questionnaire inquired about general demographics data and availability of different safety tools at their workplaces. The second section investigated the adherence of engineers and their co-workers, and the safety measures at their institution. The third section inquired about the evaluations of engineers for the awareness, adherence and effectiveness of current safety policies and available safety measures using a scale from 1 to 5 , where 1 stands for "very weak" and 5 stands for "very strong," in addition to their perceptions regarding potential safety measures that can be taken to improve current adherence rates. An informed consent was taken at the beginning of the questionnaire after describing the aims of this research. No identifying information was obtained neither about the engineers filling the questionnaire nor about their institution.

\subsection{Inclusion and exclusion criteria}

I included Jordanian engineers who are currently working in the field of civil engineering at a Jordanian housing or engineering institution, including the sub-fields of executive, supervising, and design engineers. The included engineers had a previous field working experience of at least 6 months in a project being constructed in Jordan. Moreover, I excluded engineers working in a field or sub-field not related to civil engineering or the aforementioned sub-fields.

\subsection{Statistical Analysis}

SPSS (SPSS Inc., version 22.0, Chicago, Illinois, USA) software was used for analyzing collected data. Descriptive statistics were used first to study the sample. Independent sample t-test was used to compare means between groups, while Chi-squared $\left(\chi^{2}\right)$ test was applied for categorical variables. I ran regression analysis to investigate the correlations within the evaluations of engineers for the awareness, adherence and effectiveness of current safety policies and available safety measures. The statistical significance for those two tailed statistical tests was P-value less than 0.05 .

\section{RESULTS}

Overall, 119 engineers were included in this study, of which 98 $(82.4 \%)$ were males and $21(17.6 \%)$ were females. The mean age of the study subjects was $36.2 \pm 12.5$ years, of which 59
(49.6\%) were executive engineers, 39 (32.8\%) were supervising engineers, and 21 (17.6\%) were design engineers.

The most available safety tool were helmets $(73.9 \%)$, followed by safety boots $(66.4 \%)$ and scaffolds $(63 \%)$, while only $14.3 \%$ did not have any safety tools at the construction site [Figure 1]. Most of the engineers were adherent to safety measures at the construction site $(81.5 \%)$. However, based on the engineers feedback regarding the adherence of their construction workers and site personnel, $37(31.1 \%)$ confirmed that their staff used the available safety tools under all circumstances, while 28 $(23.5 \%)$ of engineers expected that their staff used them only when the supervising engineers were present, and 27 (22.7\%) suspected that they used those tools only upon the presence of administrative staff. Remarkably, 27 (22.7\%) did not use the available safety tools as indicated [Table 1].

A significant correlation was found between attending occupational safety workshops and adherence to occupational safety, with $44(95.7 \%)$ of the 46 attendees of those workshops being adherent to occupational safety $(\mathrm{p}=0.002)$. Attending first aid workshops followed the same trend, with 38 (95\%) of the 40 attendees being adherent to safety measures $(\mathrm{p}=0.007)$. Moreover, more adherent engineers confirmed the presence of accidents and incidents logbook at their current workplace $(\mathrm{p}=$ $0.018)$. Noticeably, even though $14(66.7 \%)$ of the 21 engineers with previous injuries were adherent to safety measures, the relationship was not statistically significant $(\mathrm{p}=0.053)$. On the other hand, having a formal institutional punishment for nonadherence was statistically significant $(\mathrm{p}=0.016)$, with 28 $(96.6 \%)$ of engineers whose institutions have a punishment regulations being adherent to use PPE safety equipment.

Remarkably, 101 (84.9\%) reported previously having an injured worker at the site of construction, of which $19(16 \%)$ were severely injured. Of those 101 engineers, $28(27.7 \%)$ recommended the presence of formal punishment for nonadherence as a factor to reduce construction site injuries $(\mathrm{p}=$ $0.044), 71(70.3 \%)$ believes that injuries happened due to having unqualified workers with no formal training for the use of PPE $(\mathrm{p}=0.01)$. While $49(48.5 \%)$ believes that these workers were not trained enough prior to starting their fieldwork $(p=0.039)$. On the other hand, of the $18(15.1 \%)$ engineers with no reported workers injury, $10(55.6 \%)$ believes that the workers used safety tool only when the supervising engineers were present $(\mathrm{p}=0.004)$

On the contrary, $21(17.6 \%)$ engineers reported being injured, of which $13(61.9 \%)$ reported the lack of PPE safety tools as a factor related to occupational injuries $(\mathrm{p}=0.016)$. Interestingly, $17(81 \%)$ of injured engineers denied the presence of accidents and incidents logbook at the site of construction $(\mathrm{p}=0.008)$. Of the 21 injured engineers, $10(47.6 \%)$ reported that their workers did not use the available safety tools as indicated $(\mathrm{p}=0.009)$, upon investigating their workers' adherence.

The main factor that is believed to be linked to non-adherence of workers to safety rules at construction sites was the lack of formal punishment for non-adherent workers (67.2\%), followed by having workers who were not trained enough prior 
International Journal of Engineering Research and Technology. ISSN 0974-3154, Volume 13, Number 2 (2020), pp. 339-344

(C) International Research Publication House. https://dx.doi.org/10.37624/IJERT/13.2.2020.339-344

to starting their field work $(55.5 \%)$. Peculiarly, $49.6 \%$ of engineers believed that workers being not convinced with the efficacy of safety tools and measures being a factor for nonadherence [table 2].

Table 1: Engineer's responses regarding the current site safety policy at their current working sites.

\begin{tabular}{|c|c|c|}
\hline \multicolumn{2}{|l|}{ Characteristic } & Number (percent) n (\%) \\
\hline \multicolumn{2}{|l|}{ Occupational safety workshops } & $46(38.7)$ \\
\hline \multicolumn{2}{|l|}{ First aid workshops } & $40(33.6)$ \\
\hline \multicolumn{2}{|l|}{ First aid kit } & $79(66.4)$ \\
\hline \multicolumn{2}{|l|}{ Safety signs } & $85(71.4)$ \\
\hline \multicolumn{2}{|l|}{ Safety officer } & $67(43.7)$ \\
\hline \multicolumn{2}{|l|}{ Accidents and incidents logbook } & $54(45.4)$ \\
\hline \multicolumn{2}{|l|}{ Previous occupational injury } & $21(17.6)$ \\
\hline \multirow[t]{3}{*}{ History of injured colleague } & No & $18(15.1)$ \\
\hline & $\begin{array}{l}\text { mild-moderate } \\
\text { injury }\end{array}$ & $82(68.9)$ \\
\hline & severe injury & $19(16)$ \\
\hline \multirow[t]{3}{*}{ insurance for occupational injuries } & yes & $51(42.9)$ \\
\hline & no & $32(26.9)$ \\
\hline & uncertain & $36(30.3)$ \\
\hline \multicolumn{2}{|l|}{ formal punishment for non-adherence } & $29(24.4)$ \\
\hline
\end{tabular}

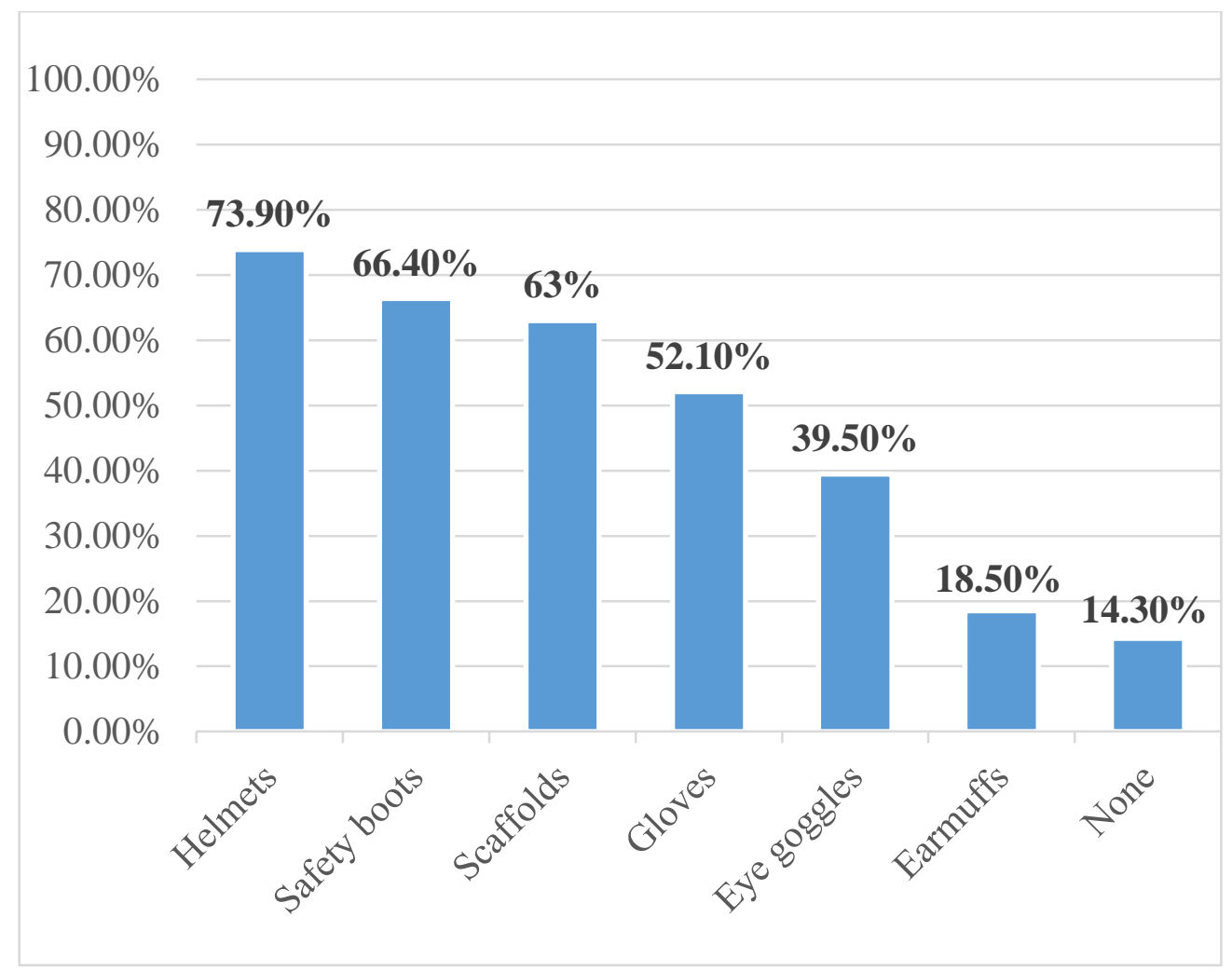

Figure 1: safety tools availability at construction sites. 
Table 2: factors that might be linked to non-adherence of workers to safety rules at construction sites.

\begin{tabular}{|l|l|}
\hline Factors & Count (percent) n (\%) \\
\hline Lack of formal punishment & $\mathbf{8 0}(\mathbf{6 7 . 2 \% )}$ \\
\hline Workers were not trained enough prior to starting their field work & $66(55.5 \%)$ \\
\hline Workers are not convinced with the efficacy of safety tools and/or measures & $59(49.6 \%)$ \\
\hline Non-adherence of supervising engineer & $53(44.5 \%)$ \\
\hline Lack of occupational safety tools & $46(38.7 \%)$ \\
\hline Unqualified workers with no formal training for occupational safety & $41(34.5 \%)$ \\
\hline Low income and long working hours & $28(23.5 \%)$ \\
\hline Untrained foreign workers & $22(18.5 \%)$ \\
\hline
\end{tabular}

Upon measuring the evaluation of engineers for the awareness, adherence and effectiveness of current safety policies and available safety measures using a scale from 1 to 5, the scores were found to be as shown in table 3 . Both the workers and engineers awareness evaluation were negatively correlated with age $(\mathrm{r}=-0.239, \mathrm{p}=0.009 ; \mathrm{r}=-0.241, \mathrm{p}=0.008$ respectively. The confidence in the effectiveness of safety policies and safety measures in preventing construction site safety hazards was significantly associated with the awareness of workers ( $\mathrm{r}=$ $0.277, \mathrm{p}=0.002)$, awareness of engineers $(\mathrm{r}=0.363, \mathrm{p}<0.001)$, and the adherence of co-workers $(r=0.34, p<0.001)$. The adherence was significantly correlated with the awareness of workers $(r=0.742, p<0.001)$, and engineers $(r=0.656, p$ $<0.001)$. Additionally, the awareness of workers was significantly associated with the awareness of engineers $(\mathrm{r}=$ $0.712, \mathrm{p}<0.001)$.

Table 3: The evaluation of engineers for the awareness, adherence and effectiveness of current safety policies and available safety measures. Evaluation was measured on a scale from 1 to 5, where 1 stands for "very weak" and 5 stands for "very strong".

\begin{tabular}{|l|l|l|l|l|l|l|}
\hline Engineers' evaluation & Overall & Adherent & p- value & $\begin{array}{l}\text { Employee } \\
\text { injured }\end{array}$ & p- value & $\begin{array}{l}\text { Engineer } \\
\text { himself } \\
\text { injured }\end{array}$ \\
\hline $\begin{array}{l}\text { Workers' awareness } \\
\text { regarding safety } \\
\text { measures }\end{array}$ & $2.65 \pm 1.05$ & $2.77 \pm 1.08$ & $\mathbf{0 . 0 0 6}$ & $2.62 \pm 1.11$ & 0.419 & $2.14 \pm 0.96$ \\
\hline $\begin{array}{l}\text { Engineers' awareness } \\
\text { regarding safety } \\
\text { measures }\end{array}$ & $3.35 \pm 1.07$ & $3.54 \pm 0.99$ & $<\mathbf{0 . 0 0 1}$ & $3.27 \pm 1.09$ & $\mathbf{0 . 0 3 8}$ & $2.9 \pm 1.18$ \\
\hline $\begin{array}{l}\text { Co-workers adherence } \\
\text { (n) }\end{array}$ & $2.96 \pm 1.11$ & $3.16 \pm 1.06$ & $<\mathbf{0 . 0 0 1}$ & $2.92 \pm 1.13$ & 0.388 & $2.29 \pm 1.1$ \\
\hline $\begin{array}{l}\text { Confidence in the } \\
\text { effectiveness of safety } \\
\text { policies and safety } \\
\text { measures in preventing } \\
\text { occupational hazards }\end{array}$ & $3.76 \pm 1.01$ & $3.84 \pm 0.99$ & 0.073 & $3.72 \pm 1.04$ & 0.392 & $4.05 \pm 0.97$ \\
\hline
\end{tabular}




\section{DISCUSSION}

The main determinant factors in achieving a healthy and safe working environment is to ensure that health and safety issues are planned, organized, monitored and reviewed [8]. In a previous study conducted in Jordan, only $66 \%$ of the 70 participating contracting organizations indicated that they have an organizational safety policy, and only $13 \%$ of these firms provided a formal safety training for most of their workers [9]. In a study conducted on subcontractors in Palestinian construction industry, the injury rate declined among subcontractors and workers if new workers are trained well in job tasks, informed about occupational risks and associated insite hazards. Moreover, a workable strategic site safety plan reduced occupational accident rates [10]. In the current study, only $38.7 \%$ and $33.6 \%$ of engineers confirmed the presence of occupational safety workshops and first aid workshops at their institutions, respectively. Approximately $43.7 \%$ of them had a safety officer or engineer at the site of construction. Both of these workshops were proven to play a significant role in increasing the adherence among our study subjects, thus I recommend a formal occupational safety and first aid training the presence of safety engineer at the site of construction, as well as regular safety meetings to provide both a feedback for construction workers and updated information about safety practices.

In our study, only $14.3 \%$ did not have any safety tools at the construction site, while in the aforementioned study by Mohammad et al (2010), 6\% of contractors confirmed that PPE are not available, while it was rarely available in $10 \%$, and sometimes available in $32 \%$. Furthermore, safety signs were available always or most of the time in $48 \%$ of the studied firms, compared to $71.4 \%$ in our study. The lack of warning and safety signs and PPE were ranked among the commonest factors related to on-site injuries, such as slipping [11, 12]. Of the $21(17.6 \%)$ engineers reporting being injured, $61.9 \%$ reported the lack of PPE safety tools as a factor related to their occupational injuries $(\mathrm{p}=0.016)$. Therefore, formal action should be taken to ensure the availability of safety tools at construction sites in Jordan [13].

Since being unaware of potential occupational hazards puts many workers at an increased risk [14], I recommend organizing regular meetings to educate workers about potential hazards in different environments, training them for using PPE, discussing most recent updates in safety guidelines and sharing updated figures of the effectiveness of these PPE and safety regulations in decreasing the rates of occupational injuries. Project managers and site engineers who reported injuries among construction workers in their projects related these injuries to the lack of PPE on site and the lack of awareness of their use [9]. Moreover, Tanko and Anigbogu (2012) demonstrated that workers in Nigeria understood the need to use the PPE, but the issues of comfort and equipment interference with their productivity limited their use [4]. PPE can be more effective if they were chosen based on intended use, they were properly maintained and certified, and workers were trained for competent and proper use of available tools [14].
Construction industry is one of the main pillars of the national economy of many Middle Eastern countries [15]. For example, construction industry in Saudi Arabia employs $15 \%$ of their total labor force [16]. Hence, accidents and incidents record keeping plays an essential role in improving the quality of the national economy by continuously improving safety program and performance $[3,17]$. In the present study, only $45.4 \%$ of engineers had an accidents and incidents logbook at their institution. To achieve a better sustainable excellence in all aspects of performance, all Jordanian institutions need to provide an accidents and incidents logbook at their institution, in order to improve their safety strategy [18].

The main factor linked to non-adherence of workers to safety rules at Jordanian construction sites is the lack of formal punishment for non-adherent workers $(67.2 \%)$, followed by the lack of sufficient training prior to starting field work (55.5\%), and workers awareness regarding efficacy of PPE (49.6\%), while the least common factor was untrained foreign workers (18.5\%) [Table 2]. Moreover, adherence was significantly correlated with the evaluation of workers' awareness $(\mathrm{r}=0.742$, $\mathrm{p}<0.001)$, and engineers' awareness $(\mathrm{r}=0.656, \mathrm{p}<0.001)$. Moreover, the confidence in the effectiveness of safety policies and safety measures in preventing construction site safety hazards was significantly associated with the awareness of workers $(r=0.277, p=0.002)$, awareness of engineers $(r=0.363$, $\mathrm{p}<0.001)$, and the adherence of co-workers ( $\mathrm{r}=0.34, \mathrm{p}<0.001)$. In Egypt, the most significant factors affecting the safety performance were found to be the safety awareness of company's top management, followed by safety awareness of project managers, and safety inspections by safety supervisor [18]. Lack of an adequate system of workplace inspection was considered one of the main factors related to non-adherence in Saudi Arabia [19], while governmental regulations, legislation and policies were regarded as the chief factor for noncompliance in a previous study conducted in Jordan, followed by management commitment and involvement, while workers awareness came third [20].

This main limitation of this study is that it did not assess construction workers' awareness, adherence and confidence in the effectiveness of current safety policies and available safety measures, in addition to worker-related factors that can be linked to workers non-adherence. Moreover, I did not compare between small-sized construction firms and larger ones. Furthermore, accidents and incidents analysis can be done in future studies to assess their frequencies and risk factors, in order to achieve our ultimate goal in providing a safer work environment.

\section{CONCLUSIONS}

In conclusion, it is obvious that not all PPE are available in most construction sites in Jordan, the most available PPE are safety helmets and safety boots, and most of the construction workers only used them when the supervising engineering staff are present. Occupational safety workshops and first aid workshops were proven to play a significant role in increasing the adherence among engineers and workers. Moreover, adherence was significantly higher among firms that imposed a sort of formal punishment on non-adherence. Lastly, engineers 
and workers who are adherent to safety regulations play a significant role in the improvement of occupational safety, and therefore Jordanian construction industry.

\section{Data Availability}

The data used for this study is available upon request to corresponding author.

\section{Conflicts of Interest}

The author declare that he has no conflicts of interest.

\section{Funding Statement}

Nil.

\section{REFERENCES}

[1] Izudi J, Ninsiima V, Alege JB. Use of personal protective equipment among building construction workers in Kampala, Uganda. Journal of environmental and public health. 2017;2017.

[2] Abdelhamid TS, Everett JG. Identifying root causes of construction accidents. Journal of construction engineering and management. 2000;126(1):52-60.

[3] Kartam N, Flood I, Koushki P. Construction safety in Kuwait: issues, procedures, problems, and recommendations. Safety Science. 2000;36(3):163-84.

[4] Tanko BL, Anigbogu N, editors. The use of personal protective equipment (PPE) on construction sites in Nigeria. WEST AFRICA built environment research (WABER) conference 24-26 July 2012 Abuja, Nigeria; 2012.

[5] Mohd Amir Shazwan H, Ee JM. Effectiveness of Personal Protective Equipment (PPE) at Construction Site. INTI Journal. 2018;1(12):1-12.

[6] Muema LM. Evaluation of Personal Protective Equipment Utilization among Construction Workers in Mombasa County, Kenya: COHES, JKUAT; 2017.

[7] Zin SM, Ismail F. Employers' behavioural safety compliance factors toward occupational, safety and health improvement in the construction industry. Procedia-Social and Behavioral Sciences. 2012;36:74251.

[8] Giessa MM, Rashid IA, El-Soud SA, El-Tahan AH. COSTING THE HEALTH AND SAFETY IN THE EGYPTIAN BUILDING CONSTRUCTION PROJECTS. Journal Of Al Azhar University Engineering Sector. 2017;12(42):167-74.

[9] Mohammad S, Al-Smadi BM, Hyari KH, Rababeh SM. Safety management in the Jordanian construction industry. Jordan Journal of Civil Engineering. 2010;4(1):47-54.
[10] Enshassi A, Choudhry RM, Mayer PE, Shoman Y. Safety performance of subcontractors in the Palestinian construction industry. Safety performance of subcontractors in the Palestinian construction industry. 2008;13(1).

[11] Enshassi A, Shakalaih S. Construction workers fall accidents from Scaffolding in Gaza Strip. Construction workers fall accidents from Scaffolding in Gaza Strip. 2015.

[12] Enshassi A, Choudhry R, Abualqumboz M. Quality and safety in the palestinian construction industry. Revista Ingeniería de Construcción (Journal of Construction Engineering). 2009;24(1):49-78.

[13] Enshass A, Choudhry RM, Aqaad M. IDENTIFING CAUSES OF SAFETY DEGRADATION IN CONSTRUCTION PROJECTS IN PALESTINE. International Journal of Construction Project Management. 2013;5(1):3.

[14] Tam VW, Fung I. A study of knowledge, awareness, practice and recommendations among Hong Kong construction workers on using personal respiratory protective equipment at risk. The Open Construction and Building Technology Journal. 2008;2(1).

[15] Dorji K, Hadikusumo BH. Safety management practices in the Bhutanese construction industry. Journal of Construction in Developing Countries. 2006;11(2):5375 .

[16] Jannadi OA, Bu-Khamsin MS. Safety factors considered by industrial contractors in Saudi Arabia. Building and Environment. 2002;37(5):539-47.

[17] Awwad R, Jabbour M, El Souki O, editors. Safety Practices in the Lebanese Construction Market: Contractors' Perspective. ISARC Proceedings of the International Symposium on Automation and Robotics in Construction; 2014: IAARC Publications.

[18] Mohamed S, Chinda T, editors. Organisational safety culture: a system dynamics approach. Proceedings of the W99 4th Triennial International Conference for Rethinking and Revitalizing Construction Safety, Health Environment and Quality; 2005: Port Elizabeth.

[19] Erogul MS, Alyami MM. Construction site safety in small construction companies in Saudi Arabia. International Journal of Management Practice. 2017;10(4):406-21.

[20] Zaid Alkilani S, Jupp J, Sawhney A. Issues of construction health and safety in developing countries: a case of Jordan. Australasian Journal of Construction Economics and Building, The. 2013;13(3):141. 